\title{
Using group work to harness students' multilinguistic competencies for a better understanding of assignment questions
}

\author{
Manduth Ramchander \\ Durban University of Technology \\ Corresponding author: Manduthr@dut.ac.za
}

(Submitted: 26 April 2020; Accepted: 29 July 2020)

\begin{abstract}
In South Africa, it is readily acknowledged that there is an absence of pedagogy to inform multilanguage usage for students for whom English is not a first language. Equally noteworthy, is that while group work has been used extensively as an active learning methodology, which has not been explored to the same extent is the manifestation of translanguaging when working in groups. This study explored how best to harness students' multilingual competencies for a better understanding of assignment questions. The population comprised of first year Business Communication students at a university of technology. A mixed method research design revealed that when multilingual students engaged in group work, there was a tendency of gravitation towards translanguaging which resulted in students having a better understanding of assignment questions. It was concluded that group work can serve as an enabler for translanguaging, harnessing students' multilingual competencies for a better understanding of their work.
\end{abstract}

Key words: group work, multilingual, multilingualism, multilinguistic, translanguaging

\section{Introduction}

The massification of the South African Higher education sector has resulted in a student population that is characterised by a growth in diversity (Smit, 2012), for many of whom, English is not the first language. However, English continues to be the dominant medium of instruction (Nudelman, 2015). Furthermore, the resultant mismatch between the language competencies of the students and academic staff presents a challenge to teaching, learning, and assessing (Department of Higher Education and Training, 2017).

Students' understanding of assignment questions is an important aspect to addressing the requirements for an assignment. If students misinterpret assignment questions, it will most likely result in a poor grade, especially if the module assessment strategy is heavily weighted on the submission of a series of individual assignments. In the normal course of teaching practice, the author has observed that there are instances of students who misinterpret assignment questions, due to language issues, resulting in them obtaining poor course marks. With no immediate solution to close the language competency chasm between the lecturer, who is a monolingual 
English language speaker, and the students, who are predominantly not English first language speakers, it became apparent that deeper reflection was required.

Dewey's (1933) problem identification, reflection, and proposed solution sequence of actions, together with Larrivee's (2000) critical reflection framework, was used to problematize and seek a solution to the current situation relating to the misunderstanding of assignment questions. It was envisaged that harnessing students' multi-linguistic competencies through group work could assist students to better understand assignment questions.

\section{Context}

Post-1994, the South African Higher education student population became characterised by an accelerated growth in linguistic diversity, largely due to the massification of Higher Education with there being 193282 first time entrants in 2017 as compared to 164518 in 2009 (Department of Higher Education and Training, 2019). Table 1 summarises the national percentage student enrolment, the permanent teaching staff profile and student success rate, according to race.

Table 1: Percentage student enrolment, permanent teaching staff and student success rate according to race

\begin{tabular}{|l|c|c|c|c|c|}
\hline Race & African & Coloured & Indian & White & Other \\
\hline Student enrolment & $72.8 \%$ & $6.6 \%$ & $4.5 \%$ & $15 \%$ & $1.1 \%$ \\
\hline Teaching staff (Research and instruction) & $38.1 \%$ & $7.4 \%$ & $8.7 \%$ & $45.8 \%$ & \\
\hline Success rate & $80.5 \%$ & $83 \%$ & $85.7 \%$ & $89.3 \%$ & \\
\hline
\end{tabular}

Source: Adapted from Department of Higher Education and Training (2019)

In South Africa, there is a correlation between language and race: those who speak an African language as a mother tongue are generally from the African race (Marjorie, 1982). The majority of student enrolment comprises African students and despite the recent growth among African academic staff, the mismatch between the percentage teaching staff profile and student enrolment profile is clearly apparent. This presents a challenge to fostering multilingualism while at the same time ensuring that existing languages (predominantly English) do not serve as a barrier to student success (Department of Higher Education and Training, 2017). The success rate is the ratio of full time equivalent (FTE) passes divided by FTE enrolments, expressed as a percentage, which is the lowest for African students, for whom English is not a first language.

The author lectures a first year Business Communications module, at a university of technology. The assessment strategy for the module comprises continuous assessment that takes the form of a series of individual assignments and a test, with no summative examination. The assignments comprise $80 \%$ and the test $20 \%$ of the final mark for the module. The overall module 
pass rates have been relatively good, averaging $96 \%$ for the past three years, with students performing very well in the test component, thus masking the poorer performance in the assignments. One reality, for the majority of the students enrolled for the module, is that the medium of instruction is English, but English is not their first language. Furthermore, the lecturer is an English first language speaker and cannot communicate fluently in any other South African language.

\section{Problem statement}

Upon reflection on his own practice, the author observed that, year upon year, some students totally misinterpret the question/s set for individual assignments and others misunderstand parts of the assignment. Consequently, these students obtain lower marks less than they could have earned had they understood the assignment questions better. Despite the lecturer's good intentions in attempting to make the written instructions more explicit and conducting detailed class discussions on the assignments, the problem persisted, signalling that there may be a breakdown in the communication cycle between the lecturer and some students. A deeper level of reflection upon his own practice brought to the fore the lecturer's own multilingual shortcomings, but at the same time that which became apparent was the reservoir of students' multilingual competencies. Larrivee (2000: 293) contends that 'critical reflection is necessary to avoid being trapped in unexamined judgements, interpretations, assumptions and expectations'. Hence the aim of the study was to ascertain how best to harness students' multilingual competencies for a better understanding of the questions set for individual assignments. The primary research question was: Does group work foster the harnessing of student's multilingual competencies among students for whom English is not a first language? The objective was to ascertain the extent of translanguaging during group work and the influence, if any, on the spread of assignment marks.

\section{Relevance of the study}

This study recognises multilingual diversity as an untapped resource and proposes harnessing the multilingual competencies of students to overcome hurdles in misunderstanding questions set for individual assignments, through group work. Group work has been used extensively as an active learning methodology for students to gain a deeper understanding of content but has to a lesser degree been used to explore how students gravitate towards translanguaging when working in groups. The findings of this study adds to the body of evidence on how group work mediates a translanguaging space to harness students' multilinguistic competencies and in particular for a better understanding of assignment questions that are presented in English, which is not students' first language.

\section{Conceptual framework}

The conceptual framework for this study was informed by Dewey's (1933) ground-breaking work, where he asserted that the capacity to reflect is initiated only after the recognition of a problem 
and the resultant dissonance created provides the impetus to engage the reflective thinker to actively critique the status quo and generate new hypotheses. Embedded within this conceptual framework is one of the four levels of reflection as described by Larrivee (2008), namely critical reflection. The tenets of critical reflection resonate well with Dewey's (1993) assertion as it is only at this level that the status quo is challenged. The conceptual framework envisaged for this study is illustrated in Figure 1.

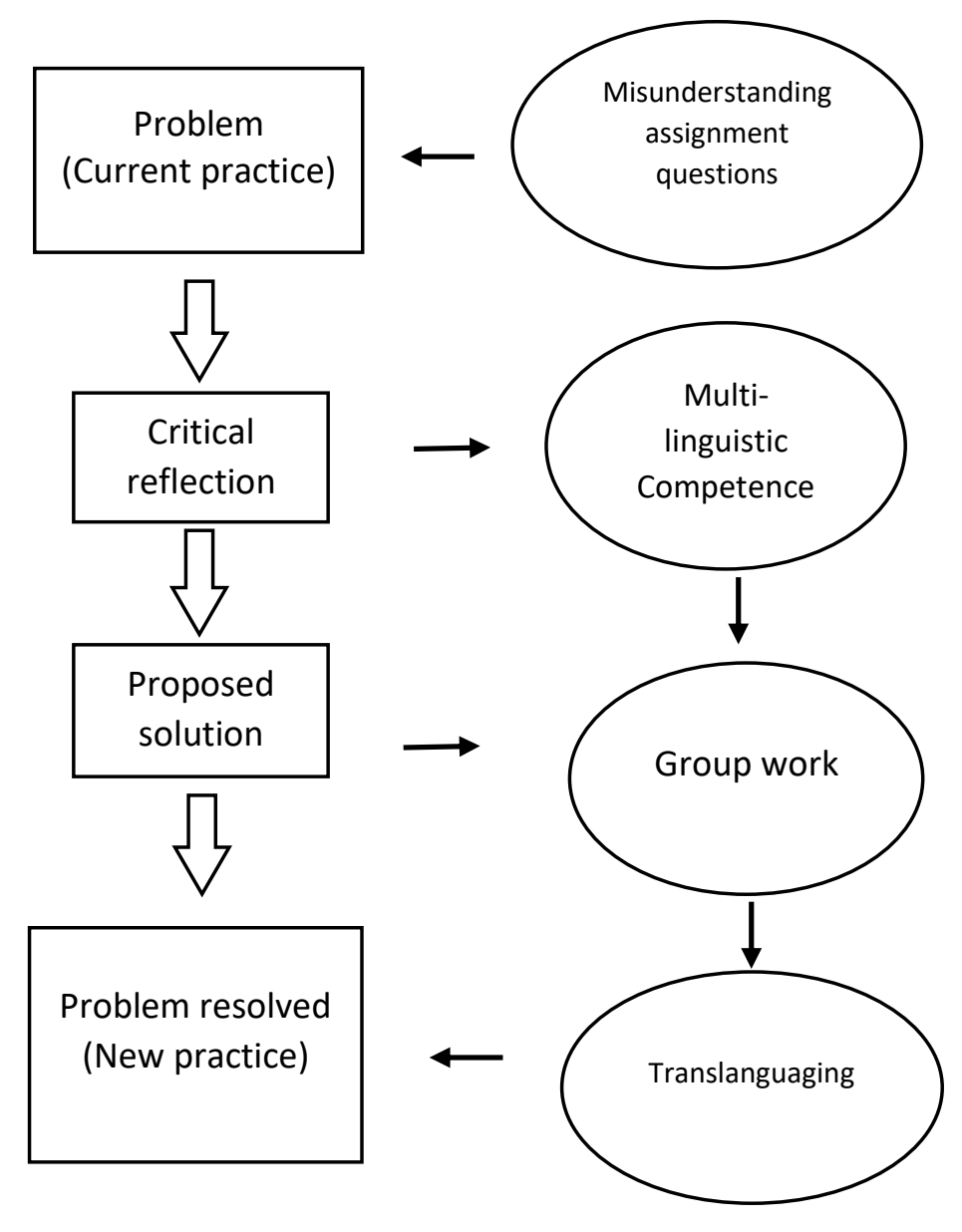

Figure 1: Conceptual framework

This study is premised on the notion of problematizing the instance of students' misinterpreting assignment questions which initiated a critical reflection process that sought to solve the problem. It was envisaged that tapping into student's multilingual competencies may help in resolving students' misinterpretation of assignment questions. It was envisaged that group work could serve as an enabler within which translanguaging could manifest and flourish. This small-scale study therefore tests this proposition wherein the majority of students are already competent in one or more South African languages, with English not being their first language. 


\section{Literature review}

Vermunt (2014) contends that it is not sufficient to just teach the subject-matter well and motivate students to learn, bringing into focus the role of the teacher as a diagnostician and reflector of students' learning processes. In an action research study, Briscoe (2017) found that the particular belief held by teachers that they are putting in their best efforts and can do nothing more to assist students to perform well, may in itself pose a barrier to more effective teaching. Liu (2015) emphasises that one of the lecturers' key competencies should be the ability to analyse and adapt their teaching to students in specific contexts, especially when teaching students who are culturally and ethnically diverse. Saric and Steh (2017) add that this requires the ability to reflect critically. Drawing upon definitions from various sources, Tripp and Rich (2012: 678) consider reflection to be 'a self-critical, investigative process wherein teachers consider the effect of their pedagogical decisions on their situated practice with the aim of improving those practices'.

Critical refection involves the examination of personal and professional belief systems, as well as the deliberate consideration of the implications and impact of practices, encompassing both the capacity for critical inquiry and self-reflection (Larrivee, 2000). The former involves the conscious consideration of classroom practices and the latter adds the dimension of deep examination of personal values and beliefs, embodied in the assumptions teachers make and the expectations they have for their students (Larrivee, 2000).

The four reflective levels as summarised by Larrivee (2008) are:

(i) Pre-reflection: A survival mode where the teacher views the ownership of problems to others (students and system) without the consideration for alternatives and failing to consider differing needs of learners, thus defending rather than analysing teaching practices;

(ii) Surface reflection: A mode where the teacher reacts to the student differentially but fails to recognize patterns of learning and modifies teaching without questioning underlying assumptions;

(iii)Pedagogical reflection: A mode where the teacher accepts responsibility for his or her own professional practice, analysing the impact of instructional methods on learning, seeking out new ways to connect concepts to student's prior knowledge, interest and curiosity.

(iv)Critical reflection: A mode where the teacher views his or her own practice within broader cultural, sociological, historical, and political contexts, challenging the status quo, especially with respect to power and control, thus addressing issues of equity and social justice that arise in and outside of the classroom.

According to Larrivee (2000), the critical reflection process weaves through the following series of phases:

(i) Examination stage: challenges and questions whether current practices are achieving objectives, initiating a desire for change; 
(ii) Struggle: facing conflict and surrendering what is familiar and allowing oneself to experience uncertainty; and

(iii)Perceptual shift: deeper understanding emerges that allows one to reconcile with new practice.

Briscoe (2017) posits that lessons should be aligned to students' ways of knowing and tapping into students' prior knowledge, for the activation of learning. Several studies, both local and international, evidence that the utilisation of students' own language can facilitate greater cognition and, consequently, leads to success in education (Cummins, 2000; Dlodlo, 1999; Heugh, 2003; Kapp and Bangeni, 2011; Madiba, 2010b). Briscoe (2017) contends that learning is more meaningful when students feel that their realities are reflected in teaching and by implication in assessment practices, as the one cannot be separated from the other.

García and Sylvan (2011: 398) argue that 'monolingual education is no longer relevant in our globalized world'. Madiba (2010a) contends that an English-only policy is not feasible for a university environment. In this regard, even though the draft language policy for higher education recognises the linguistic diversity and provides for legitimisation of South African languages in higher education, the use of English as a predominant language of teaching and learning continues to create a different educational experience for students for whom English is not the first language (Department of Higher Education and Training, 2017). The report on the use of South African languages in higher education (Department of Higher Education and Training, 2015) reveals:

(i) a growing body of research that points to the role of language in student underperformance at university;

(ii) an absence of pedagogy to inform multi-language usage to support concept formation in students for whom English is an additional language;

(iii) the inability on the part of monolingual staff to support multi-language usage as a means to facilitate concept formation; and

(iv) institutions professing respect for multilingualism but there is a lack of articulation about how multilingualism is to be accommodated in the teaching.

Multilingualism is defined as the 'effective use and promotion of multiple languages either by an individual speaker or a community of speakers' (Department of Higher Education and Training, 2017). South Africa is culturally diverse with a multitude of languages and when viewed as a valuable resource, could be harnessed by positioning South African languages at the centre of teaching and learning at universities (Mbembe, 2015). One method to achieve this, and central to this study, is group work wherein students navigate meaning by holding discussions shuttling between English and their own first languages (translanguaging) (Hendricks and Lebowitz, 2016). According to a report by Middleton (2018), the Vice-Chancellor of the University of Cape Town supports the notion of translanguaging as a means to give effect to the language policy that has otherwise remained a chimera.

Canagarajah (2011: 401) defines translanguaging as 'the ability of multilingual speakers to shuttle between languages, treating the diverse languages that form their repertoire as an 
integrated system'. Although the term "translanguaging" often appears alongside "codeswitching" within the literature, the difference becomes apparent in the ideology of the two theories (Creese and Blackledge, 2015). With code-switching the two languages of bilinguals are assumed to be two separate monolingual codes with the propensity of usage without reference to each other, while with translanguaging bilinguals have one linguistic repertoire from which they deliberately choose features for effective communication (Creese and Blackledge, 2015) without regard for language boundaries (Otheguy, et al., 2015).

In a study to ascertain the effectiveness of using a translanguaging approach to assist students in understanding texts, Mbirimi-Hungwe (2016) found that the group participants, through discussion of the main ideas from the text in their own languages, understood the main ideas of a text better, as evidenced by the summaries they produced. Group work as a pedagogical approach is grounded in active learning theory that is based on the constructivist approach to learning which emphasises that students construct their own understanding through interactions with others (Burke, 2011). The theoretical underpinning to the use of cooperative learning groups is based on the principle of constructivism, which pivots on the idea that students learn through building their own knowledge by connecting new ideas and experiences to existing ones to form new understandings (Bransford, et al., 1999). Group dialogue helps students make sense of what they are learning and what they still need to understand (Ambrose, et al., 2010; Eberlein, et al., 2008). Johnson, et al. (2014) describe this type of group work as cooperative learning, where the instructional use of small groups is employed to promote the maximization of students' own learning as well as their learning from each other.

In a study involving school science students, Tyler, et al. (2015) observed that multilingual students who debated the meaning of terms in their own languages had a deeper understanding of the terms when compared to surface level understanding of monolingual English students. Following a meta-analysis of 168 studies, Johnson et al. (2006) concluded that undergraduate students had greater knowledge acquisition, and higher-order problem solving and reasoning abilities when learning in a collaborative situation than students working alone. In another metaanalysis of 39 studies in university STEM classes, Springer, et al. (1999) found that students who participated in small-group learning had greater academic achievement than those who did not participate. Hence, the consideration of the role that group work can play in creating translanguaging spaces, is central to this study.

Race (2007) provides a clear rationale for group work, arguing that humans have evolved on the basis of group learning and learning from others is therefore instinctive. For example, Burke (2011) notes that groups have more information than individuals and tapping into this well of resources fosters learning because of a variety of backgrounds. Although group work can be fraught with pitfalls, the literature abounds on strategies that can be used to avoid these pitfalls (Hodges, 2017; Burke, 2011; Centre for Academic Development, 2013). Felder and Brent (2001) suggest that groups assigned by the instructor are more effective than self-selected groups. Csernica, et al. (2002) contend that self-selected groups often gravitate towards groupings of friends with students spending more time socializing than focusing on the task. Group size is an 
important dynamic to group work and the literature suggests the smaller groups ranging from three to five members work better than larger groups (Csernica, et al., 2002; Beebe and Masterson, 2003; Burke, 2011). Hodges (2017) articulates that it would be good practice, during group work, for the instructor to circulate around the class and take students' questions to clear up areas of confusion that may arise.

Paxton's (2009) study describes a project at the University of Cape Town wherein Economics students were placed in home language groups to construct sentences both in English and home language to enhance understanding of new concepts encountered. The study revealed that some students did not have a clear understanding of the concepts and without having the discussion in home language groups, student's incorrect perceptions of concepts may have remained undetected and thus the importance of using a range of languages and discourses to negotiate meaning (Paxton, 2009).

More recently, Middleton (2018) reported on a translanguaging project underway at the University of Cape Town, under the leadership of Professor Madiba, which aims at bringing student's multilingual resources into the classroom, where students draw upon home language and English, and calls such a practice translanguaging. It is further explained that the practical implication of translanguaging means that lecturers can make use of tutorials as translanguaging spaces. According to Middleton (2018), Professor Madiba believes that it is not necessary for lectures or tutors to be well versed in the multitude of languages that are used in discussions, since the report back can be in English. However, it would be rather short-sighted to have such spaces relegated to tutorials only and not within normal classes as well. du Buisson (2017) also gives an account of multilingual group discussions, but again this is limited to tutorials.

\section{Methodology}

This study is cross-sectional in nature and follows a mixed method quantitative/qualitative research paradigm using a case study approach. A case study research design is classified according to purpose and type (Asimiran and Njie, 2014). The purpose of this study is exploratory in nature and the type of case is an instrumental case. According to Yin (2009), an exploratory study explores situations where the outcomes for the phenomenon are unclear. In an instrumental case, the case is not of primary interest but has a supporting role in facilitating an understanding of the phenomena (Yin, 2009) as opposed to a typical case which is representative of the broader set of cases (Gerring, 2008).

The inquiry for this study was informed by Larrivee's (2000) critical reflection framework, where the current practice of students misinterpreting assignment questions was problematized and action was formulated to transform the practice. The population for this study comprised 117 students that were registered for a first year Business Communication module at the University of Technology in 2019. Students were furnished with the assignment questions, the marking rubric and the due date for the submission of the assignment, at the commencement of the module. The questions for the assignment were presented in English and the assignment comprised two sections constituting 20 marks each. The first section involved the writing of the 
notice of a meeting given a synopsis of the matters arising from previous minutes and new items to be discussed. The second section entailed the writing of conclusions and recommendations for a report where the terms of reference, methodology and results were presented.

On a selected day, three weeks prior to the assignment submission due date, convenience sampling was used to engage all students that were present in group work. Students were divided in groups of four to five members who were systematically assigned according to the class register. The task assigned to the group was for them to unpack the questions set for the assignment, by engaging in discussion with their peers. The instructions were provided in English and there was no specific instruction regarding the choice of language or languages to be used for group discussions. Students were advised that a survey would be conducted at the end of the group activity.

The duration of the group activity was about 20 minutes, at the end of which, a short survey using a closed ended questionnaire was conducted. Students were presented with a letter of information describing the study and a consent form for their voluntary participation. The anonymity of the respondents was maintained at all times and all institutional protocols with regards to ethics were strictly adhered to. Full approval for the study was obtained from the Institutional Research Ethics Committee at the University. The questionnaires were collected at the end of the lecture session as the students exited the venue. The questionnaire comprised two sections. Section A related to demographic data and Section B comprised statements that students had to respond to on a five -point Likert scale with options ranging from "strongly disagree" to "strongly agree". The content focus of the statements in Section B of the questionnaire related to student's understanding of the questions set for the assignment, before and after group work and languages used during group discussions.

The validity of the questionnaire was ensured by confirming that the items included in the questionnaires were informed by the constructs discussed in the literature review. Furthermore, methodological triangulation was employed to enhance validity. The reliability of the questionnaire was ensured by employing the split-half test on selected items that were phrased as negatives of each other. The responses to the questionnaires were analysed using descriptive and inferential statistics. While the group discussions were being conducted, the lecturer walked around the class, in line with the view articulated by Hodges (2017), taking note of whether African (non-English) languages were being used for group discussions, while at the same time assisting students with queries as they arose. The assignments were marked after they were submitted, the general performance of students was noted, and the results were statistically analysed.

Selected student's written answers were qualitatively analysed to ascertain the nature of errors made in answering the assignment questions with particular reference to those that were, at the time of marking, deemed to be cases of students misunderstanding the questions. The assignments mentioned were marked according to a marking rubric as illustrated in table 2. 
Table 2: Marking rubric for assignment

\begin{tabular}{|l|c|c|c|}
\hline Writing of Notice of meeting assignment & $\begin{array}{c}\text { Max } \\
\text { mark }\end{array}$ & Mark & Comments \\
\hline $\begin{array}{l}\text { The document heading, and the wording and ending of the notice are } \\
\text { correct }\end{array}$ & 10 & 7 & \\
\hline $\begin{array}{l}\text { Heading is given; the first } 4 \text { items on the agenda are correct; detail is } \\
\text { given where necessary }\end{array}$ & 9 & & \\
\hline $\begin{array}{l}\text { Matters Arising Items are correct with relevant headings and sufficient } \\
\text { detail given }\end{array}$ & 9 & & \\
\hline $\begin{array}{l}\text { New Items are correct with relevant headings and sufficient detail } \\
\text { given. }\end{array}$ & 9 & & \\
\hline Remaining agenda items are correct & $40 / 2=20$ & & \\
\hline Numbering follows accepted conventions & & & \\
\hline TOTAL & & & \\
\hline Writing of conclusion and recommendations assignment & 20 & & \\
\hline $\begin{array}{l}\text { The correct heading for Conclusions is given; the correct numbering is } \\
\text { used. }\end{array}$ & 2 & & \\
\hline $\begin{array}{l}\text { An attempt at an appropriate 'summary' of each finding has been } \\
\text { made }\end{array}$ & 4 & & \\
\hline The writer has 'judged' or given a meaningful opinion on each finding & 4 & & \\
\hline $\begin{array}{l}\text { The correct heading for Recommendations is given; the correct } \\
\text { numbering is used }\end{array}$ & 2 & & \\
\hline $\begin{array}{l}\text { Each recommendation is practical/possible to implement, and 'should' } \\
\text { is used in each (2 } \times \text { 4) }\end{array}$ & 8 & & \\
\hline TOTAL & & & \\
\hline
\end{tabular}

Students' assignment answers were selected on the basis of remarks made in the comments section of the rubric in the answer booklets. At the time of marking, where it was deemed that students misunderstood the question, remarks were made in the comments section to give an indication to students as to why they did not score well, otherwise the comments section was left blank. An example of a remark made was: "you have misunderstood the question!"

Students' answer booklets were retrieved from storage and for each of the years 2017 , 2018 and 2019 the student's assignments were separated into two batches. The first batch comprised student assignments where there were comments made and the second batch comprised student's assignments without any comments. The first batch of student assignments were selected for analysis. Working backwards from the comments to the answers written by students, the errors made were coded and associated themes were extracted. An example of an error made in students' writings was instead of writing ' 1 . Welcome' in the agenda section of the notice of a meeting, some students wrote: '1. Welcome: The chairperson welcomed all members', which pertains to the minutes of a meeting. 


\section{Results}

The sample characteristics in terms of gender, age and first language are represented in Table 3.

Table 3: Sample characteristics

\begin{tabular}{|l|c|c|c|c|c|c|c|}
\hline \multirow{2}{*}{$\begin{array}{l}\text { Sample } \\
\text { size }\end{array}$} & \multicolumn{2}{|c|}{ Gender } & $\begin{array}{c}\text { Average } \\
\text { age }\end{array}$ & \multicolumn{4}{|c|}{ First Language } \\
\cline { 2 - 8 } & Male & Female & Years & English & IsiZulu & IsiXhosa & Other \\
\hline $\mathbf{8 9}$ & 46 & 43 & 20 & 15 & 64 & 9 & 1 \\
\hline & $52 \%$ & $48 \%$ & & $16.9 \%$ & $71.9 \%$ & $10.1 \%$ & $1.1 \%$ \\
\hline
\end{tabular}

The sample comprised 89 students and was considered to be representative of the population size of 117 students, for a confidence level of $95 \%$ and confidence interval of $5 \%$, as verified against Sekaran and Bougie's (2016) population to sample table. The average age of respondents was determined to be 20 years. Gender was almost equally represented in the sample. While the medium of instruction was English, only fifteen students speak English as a first language. For the majority $(71.9 \%)$ of the students, IsiZulu is their first language. This was expected as the University is located in the Province of KwaZulu-Natal, where the predominant spoken language is IsiZulu.

The profile of the respondents according to race is presented in Table 4.

Table 4: Racial profile of respondents

\begin{tabular}{|l|l|l|l|l|l|l|}
\hline Race & African & Coloured & Indian & White & Other & Total \\
\hline Sample & 74 & 4 & 9 & 1 & 1 & 89 \\
\hline \% Sample & $83.2 \%$ & $4.5 \%$ & $10.1 \%$ & $1.1 \%$ & $1.1 \%$ & $100 \%$ \\
\hline
\end{tabular}

The racial profile of the respondents is reflective of the national student racial profile (Table 1) with slightly higher proportions of African and Indian students and slightly lower proportions of Coloured and White students. This is so because of the higher concentrations of the African and Indian populations in the province of KwaZulu-Natal. The large number of African students bears testimony to the massification of higher education at the institution. Table 5 depicts students' perceptions of understanding of assignment questions before and after being engaged in group work.

To determine whether the scoring patterns per statement were significantly different per statement, a chi square test was done. The chi square $p$-value was determined by combining the data for "strongly disagree" and "disagree" into one category and by combining the data for the "strongly agree" and "agree" into another category. The chi square test was then performed on the two categories. The p-values shown in Table 4 are less than 0.05 , implying that the 
distributions were not similar. The first statement shows a higher level of agreement and the second statement shows higher levels of disagreement.

Table 5: Students' perceptions of understanding of assignment questions

\begin{tabular}{|l|c|c|c|c|c|c|}
\hline Statements & $\begin{array}{l}\text { Strongly } \\
\text { disagree }\end{array}$ & Disagree & Neutral & Agree & $\begin{array}{l}\text { Strongly } \\
\text { agree }\end{array}$ & $\begin{array}{l}\text { Ci } \\
\text { Square p } \\
\text { value }\end{array}$ \\
\hline $\begin{array}{l}\text { I was able to understand } \\
\text { the questions set for the } \\
\text { assignment better after } \\
\text { the group discussion }\end{array}$ & $7.9 \%$ & $5.6 \%$ & $12.4 \%$ & $55.0 \%$ & $19.1 \%$ & 0.000 \\
\hline $\begin{array}{l}\text { I understood the } \\
\text { assignment questions } \\
\text { perfectly well prior to } \\
\text { the group discussion }\end{array}$ & 11 & 52 & 11 & 10 & 5 & 0.000 \\
\hline
\end{tabular}

Just over $74 \%$ of the respondents agreed or strongly agreed that they were able to understand the questions for the assignment better after the group discussion. In resonance with this, $70.8 \%$ disagreed or strongly disagreed that they understood the assignment questions perfectly well prior to the group discussion. The statements were so pitched that the one was the negative of the other so that a more positive response for one would require a more negative response for the other and vice versa. This was so done to ensure reliability using the split-half test. The reliability statistics is reflected in Table 6 .

Table 6: Reliability statistics

\begin{tabular}{|c|c|c|c|}
\hline \multirow[t]{5}{*}{ Cronbach's Alpha } & \multirow[t]{2}{*}{ Part 1} & Value & 1,000 \\
\hline & & $N$ of Items & $1^{\mathrm{a}}$ \\
\hline & \multirow[t]{2}{*}{ Part 2} & Value & 1,000 \\
\hline & & $\mathrm{N}$ of Items & $1^{b}$ \\
\hline & \multicolumn{2}{|l|}{ Total $\mathrm{N}$ of Items } & 2 \\
\hline \multicolumn{3}{|l|}{ Correlation Between Forms } & 0,906 \\
\hline \multirow[t]{2}{*}{ Spearman-Brown Coefficient } & \multicolumn{2}{|l|}{ Equal Length } & 0,950 \\
\hline & \multicolumn{2}{|l|}{ Unequal Length } & 0,950 \\
\hline
\end{tabular}

Due to negative phrasing, reverse coding was performed on the results of the second statement. The Spearman-Brown Coefficient (0.950) demonstrates excellent reliability indicating that students responded to both the statements in a similar manner. Thus, together the higher level of agreement to the first statement and higher level of disagreement in the second 
statement demonstrates that students took the survey seriously and did not just insert responses without reading or thinking about the statements. It may, therefore, be concluded that respondents perceived group work to have a positive influence on their understanding of the assignment questions.

The class was divided into 17 groups of five students and one group of four students. While walking around the class the lecturer noted that, in most of the groups, discussions were being conducted in a mixture of English and home languages. However, as the lecturer approached closer to the groups, the discussion reverted to English only. It was also noted that as the lecturer moved away from the group, the discussion reverted to a mixture of English and home language. Having become aware of this, after the first two group observations, the lecturer stood just within earshot of a group. It was observed that in all but two groups, students shuttled between the use of English and a home language. However, while it was clear that African languages were being used, it was not clear as to exactly which African languages were being used due to the lecturer not being a speaker of any of the African languages. The extent to which different languages were used in group discussions was determined by analysing students' responses in the survey, wherein students were required to select options with regards to languages used in group discussions. The languages, from a number of options, were categorised as depicted in Table 7.

Table 7: Languages used in group discussions

\begin{tabular}{|l|l|l|l|l|}
\hline \multicolumn{4}{|l|}{ Languages used in Group discussions } & \multirow{2}{*}{ Total } \\
\cline { 1 - 4 } English only & English and both IsiZulu and IsiXhosa & English and IsiZulu & English and IsiXhosa & \\
\hline 10 & 9 & 61 & 10 & 89 \\
\hline
\end{tabular}

The majority of the students reported that the group discussions were held in English and IsiZulu. Only a few reported that the group discussions were held in English only, English and IsiXhosa or English, and both IsiZulu and IsiXhosa. The first language for the majority of the students is Isizulu (Table 2), thus it is not surprising that the discussions in most of the groups were held in English and IsiZulu. Although the data was analysed on an individual basis and not on a group basis, ten students reported that the discussions in their groups were held in English only and this triangulates well with the lecturer's observation while circulating among the groups. At face value, there seemed to be nothing unique about the two groups with regard to demographic profile.

The extent to which translanguaging was taking place was determined by analysing students' responses on the extent to which they agreed or disagreed with the following statement: 'When working in groups it was common for the discussion to frequently shift between the usage of English and Home Language'. The translanguaging between English and home language is evident as can be deduced from the students' responses as illustrated in Figure 1. 
Translanguaging between English and Home language

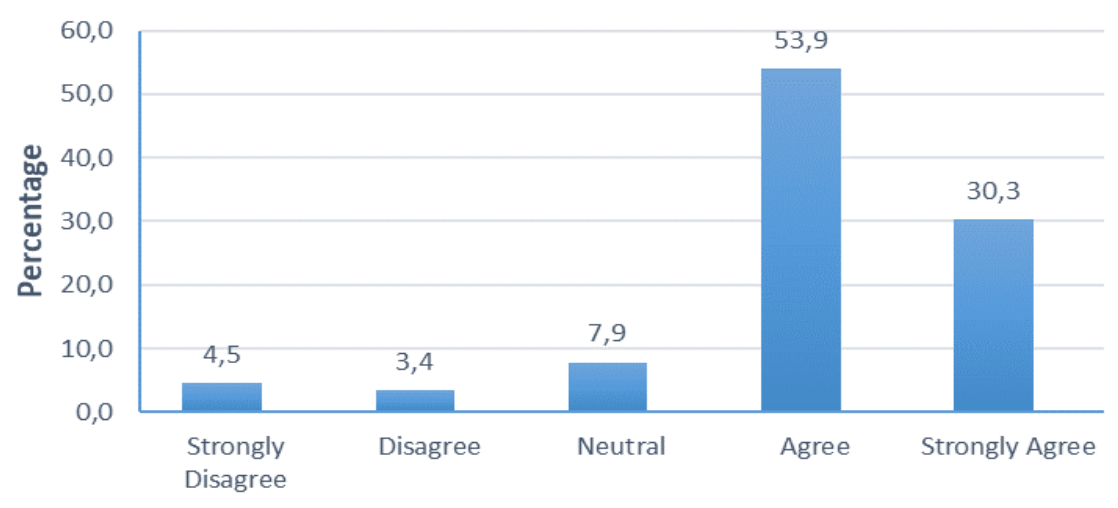

Figure 1: Translanguaging between English and Home language

The majority (84.2\%) of the students agreed or strongly agreed with the statement. To determine whether the scoring pattern was significantly different for the "agree/disagree" categories, a chi square test was done. The p-value was found to be less than 0.05 (0.000), implying that the distributions were not similar. The responses to the statement show higher levels of agreement than disagreement. It may be concluded that when working in groups, students translanguage between English and home language. Thus, group work can address the problem of the inability on the part of monolingual staff to support multi-language usage as a means to facilitate concept formation education (Department of Higher Education and Training, 2015).

Figure 2 illustrates the responses to the statement: "I have a better understanding of the assignment questions after group members explained it to me in my home language".

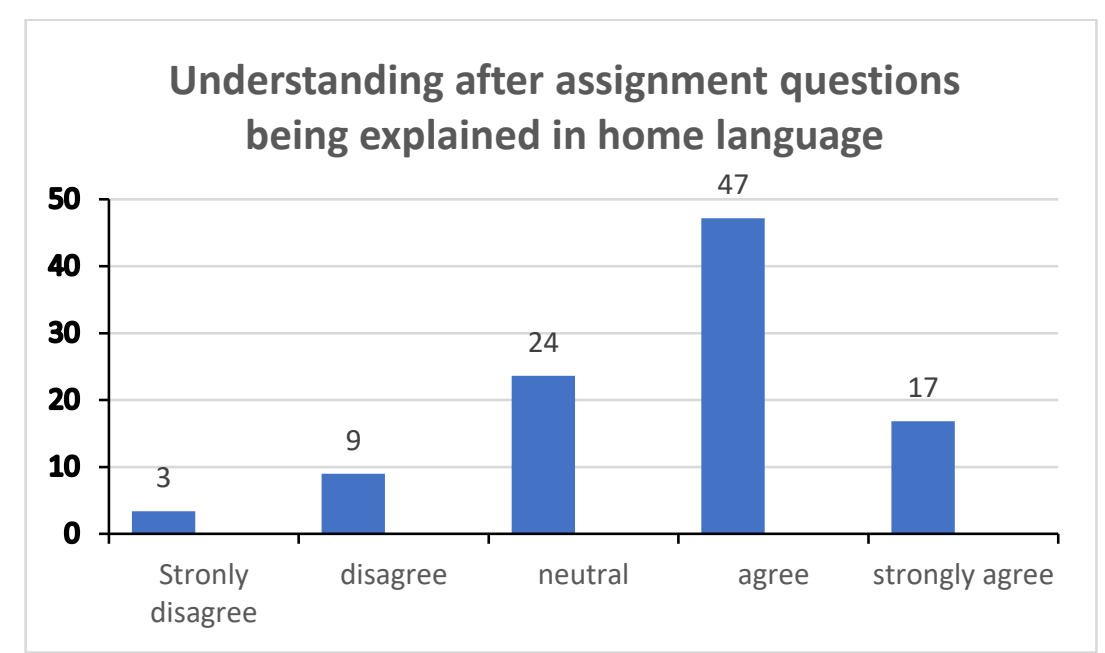

Figure 2: Understanding after assignment questions being explained in home language

The majority $(64.1 \%)$ of the students agreed or strongly agreed with the statement. To determine whether the scoring pattern was significantly different for the "agree/disagree" categories, a chi square test was done. The p-value was found to be less than 0.05 (0.000), 
implying that the distributions were not similar. The responses to the statement show higher levels of agreement than disagreement. Thus, it may be concluded that students were able to get a better understanding of the assignment questions after they were explained to them in their home language by other group members. This finding is in keeping with the findings from several other studies (Cummins, 2000; Dlodlo, 1999; Heugh, 2003; Kapp and Bangeni, 2011; Madiba, 2010b) that the utilisation of students' own language can facilitate greater cognition.

The assignment and assignment questions that were set for the different cohorts of students in the years 2017, 2018 and 2019 were identical. Students' assignment marks for the past three years were analysed and the results are illustrated in Figure 3.

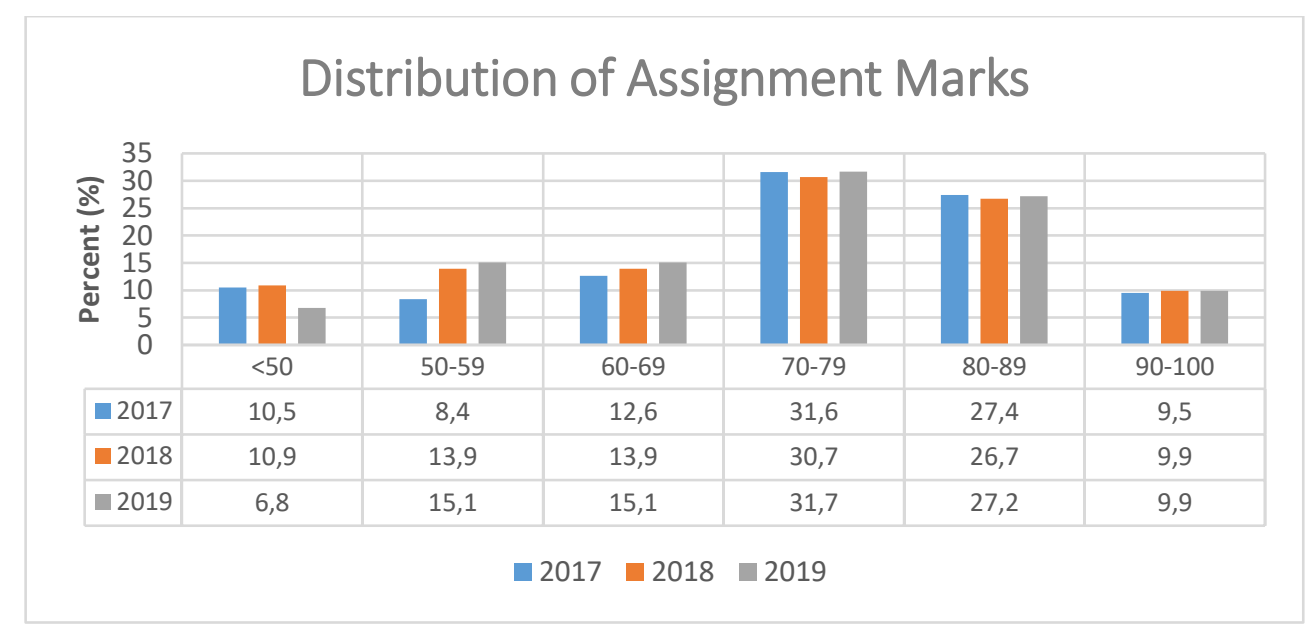

Figure 3: Distribution of Assignment Marks

The best results for the assignment were in 2019 as is evidenced by a smaller percentage of students failing with greater percentages of students scoring in the 50-59 and 60-69 percentage categories. The spread of assignment marks for the years 2017 to 2019, illustrated in the box and whisker plot in Figure 4, gives another view of the data.

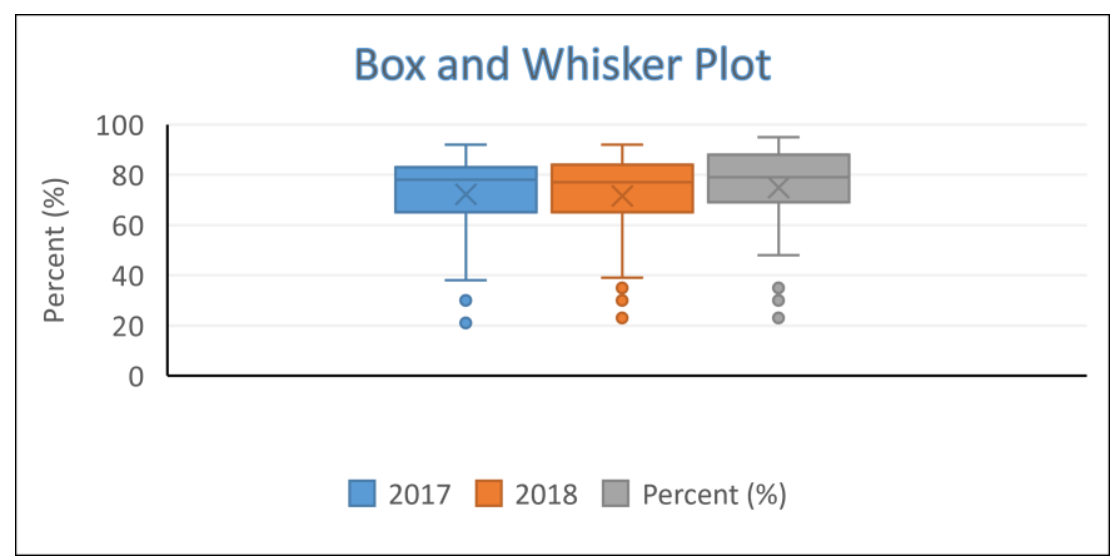

Figure 4: Box and whisker plot for assignment marks for the period 2017 to 2019

The box and whisker plot illustrates that the overall performance was much better for 2019 when compared to 2017 and 2018. 
The qualitative analysis of the student's writings is synthesised in Table 8.

Table 8: Summary of analysis of student's answers

\begin{tabular}{|c|c|c|c|}
\hline $\begin{array}{l}\text { Comments used for the identification of } \\
\text { students answers for analysis }\end{array}$ & Element & Codes & Theme \\
\hline \multirow{4}{*}{$\begin{array}{l}\text { - you have miss-understood the question! } \\
\text { - does not answer the question! } \\
\text { - what has this got to do with the question? } \\
\text { - You did not answer the question posed!! } \\
\text { - This is an answer to another } \\
\text { question/section -not this one! } \\
\text { - This answer does not relate to the question } \\
\text { posed! } \\
\text { - No! you have not answered the question } \\
\text { - You have to read the question more } \\
\text { carefully! } \\
\text { - You have misinterpreted the question } \\
\text { - No! No! No! -read the question more } \\
\text { carefully }\end{array}$} & \multirow[t]{2}{*}{$\begin{array}{l}\text { Writing of } \\
\text { minutes }\end{array}$} & $\begin{array}{l}\text { Type A: } \\
\text { Incorrect } \\
\text { format }\end{array}$ & $\begin{array}{l}\text { Structure: for minutes instead } \\
\text { of notice of meeting }\end{array}$ \\
\hline & & $\begin{array}{l}\text { Type B: } \\
\text { Correct } \\
\text { format - } \\
\text { Incorrect } \\
\text { items to } \\
\text { subsection }\end{array}$ & $\begin{array}{l}\text { Items that should have } \\
\text { appeared under matters } \\
\text { arising were placed under new } \\
\text { matters and vice versa }\end{array}$ \\
\hline & \multirow[t]{2}{*}{$\begin{array}{l}\text { Writing of } \\
\text { report }\end{array}$} & $\begin{array}{l}\text { Type A: } \\
\text { Incorrect } \\
\text { format }\end{array}$ & $\begin{array}{l}\text { Structure: Used findings to } \\
\text { present solutions without a } \\
\text { structure that separates } \\
\text { conclusion } \\
\text { recommendations }\end{array}$ \\
\hline & & $\begin{array}{l}\text { Type B: } \\
\text { Correct } \\
\text { format - } \\
\text { Incorrect } \\
\text { items to } \\
\text { subsection }\end{array}$ & $\begin{array}{l}\text { Items that should have been } \\
\text { placed under conclusion were } \\
\text { placed under } \\
\text { recommendations and vice } \\
\text { versa }\end{array}$ \\
\hline
\end{tabular}

Although the lecturer was the same for the years 2017, 2018, and 2019, the phrasing of the comments differed slightly as depicted in Table 8 . It was established that students made two types of errors. The first type of error (Type A) was critical as it led to students losing maximum marks due the structure being incorrect. An example of a type A error is the following excerpt from the agenda section of a notice of a meeting of a student's writing:

'1. Welcome: The chairperson welcomed all members

2. Attendance: Present: Sma Sokhela (Chairperson), Mrs Liza Moodley, Mr S. Zulu (Secretary), Mr Simon Zondi, Mr B.Dlamimi

3. Apologies: No apologies were received'. 
The above student's writing evidences that the student misunderstood the question thinking that he or she was required to write minutes instead of a notice of a meeting.

Another example is the following excerpt from the conclusion section of a student's writing: ' $73 \%$ of students complained that although each computer lab contained 50 or more computers, on any day at least $20 \%$ of these were not working'. The student transformed the numbers given in the findings section into percentages instead of using the findings to draw conclusions that are devoid of numbers or percentages. Students in 2019 were more successful in drawing conclusions from a set of given findings. For example, the 2019 students wrote conclusions along the lines of: 'the majority of students ...' or 'most students...', thus evidencing a transition in conceptual understanding when compared to students in 2017 and 2018.

In the second section, students did not understand that they had to use the findings presented to write separate conclusions and recommendations. This second type of error (Type B) was less critical as students lost only the marks for the entry to the incorrect subsection. An example of a type B error is the following excerpt from the conclusion section of a student's writing:

"Conclusion: The lab should not be closed, it should be open till late maybe $11 \mathrm{pm}$ or $12 \mathrm{pm}$ to give student enough time to do their work"

The above should have been presented under the heading "Recommendation" instead of "Conclusion". The extent of the two types of errors made, on a yearly basis, is summarised in Table 9.

Table 9: Extent of errors made

\begin{tabular}{|l|l|l|l|l|}
\hline Year & Enrolment & $\begin{array}{l}\text { Number of students' } \\
\text { answers identified }\end{array}$ & $\begin{array}{l}\text { Frequency of Type } \\
\text { A error }\end{array}$ & $\begin{array}{l}\text { Frequency of } \\
\text { Type B error }\end{array}$ \\
\hline 2017 & 100 & $19(19 \%)$ & high & low \\
\hline 2018 & 102 & $21(21 \%)$ & high & low \\
\hline 2019 & 117 & $9(8 \%)$ & low & low \\
\hline
\end{tabular}

The number of students' answers identified for analysis is lowest for 2019. This can be attributed to the reduced frequency of Type A errors in 2019. Thus, the qualitative data indicates that students had a better understanding of assignment questions in 2019 by virtue of fewer students having made errors relating to structure (Type A). The qualitative data triangulates well with the quantitative data analysed earlier. This can be attributed to group work wherein students navigate meaning by holding discussions through shuttling between English and their own first languages as posited by Hendricks and Lebowitz (2016). The findings of this study add to the growing body of evidence (Mbirimi-Hungwe, 2016) on the effectiveness of using a translanguaging approach that is mediated by group work. 


\section{Conclusion and recommendations}

The literature abounds with evidence of the benefits of group work as well as the benefits of translanguaging. Critical reflection initiated tapping into students' multilingual competencies using group work as a learning strategy. Noting that students are already competent in other languages, the practice was re-envisioned to draw upon the untapped reservoir of students' multilingual competencies. When multilingual students are put into groups, there is a natural gravitation towards translanguaging between the medium of instruction and home language. Translanguaging, enabled students to have a better understanding of the assignment question. Group work therefore serves as an enabler, creating the necessary space for translanguaging to manifest as a natural phenomenon. The findings do provide some insight into a possible solution for two areas of concern around languages in higher education (Department of Higher Education and Training, 2015), in particular that which relates to absence of pedagogy to inform multilanguage usage to support concept formation in students for whom English is an additional language as well as the inability on the part of monolingual staff to support multi-language usage as a means to facilitate concept formation.

Although the limitation of this study is that it was small scale, the findings could have resonance for other settings. It is recommended that group work be used as a vehicle to create the translanguaging space within which students' multilingual competencies can be harnessed for a better understanding of, not only assignments, but also for other learning experiences as well. It is also further recommended that the translanguaging spaces not be restricted to tutorial activity only but be used in normal classes as well. In doing so, South African languages could be positioned at the centre of teaching and learning at universities, as advocated by Mbembe (2015). It is recommended that further research be undertaken on how the proximity of the lecturer to the group influences the extent of translanguaging that takes place.

\section{Author Biography}

Manduth Ramchander was a schoolteacher for 20 years. He lectured Research Methodology at the University of Zululand, and thereafter Supply Chain Management at the University of KwaZulu-Natal, where he was also the Academic Leader. He currently lectures and supervises postgraduate research in the Department of Operations and Quality at the Durban University of Technology.

\section{References}

Asimiran, S. \& Njie, B. 2014. Case study as a choice in qualitative methodology. Journal of Research \& Method in Education, 4(3): 35-40.

Ambrose, S.A., Bridges, M.W., Lovett, M.C., DiPietro, M. \& Norman, M.K. 2010. How Learning Works: Seven Research-Based Principles for Smart Teaching. San Francisco, CA: JosseyBass.

Beebe, S.A. \& Materson, J.T. 2003. Communicating in Small Groups. Boston, Massachusetts: Pearson Education. 
Bransford, J.D., Brown, A.L. \& Cocking, R.R. 1999. How People Learn: Brain, Mind, Experience, and School. Washington, D.C: National Academy Press.

Briscoe, P. 2017. Using a critical reflection framework and collaborative inquiry to improve teaching practice: An action research project. Canadian Journal of Action Research, 18(2), 43-61.

Burke, A. 2011. Group work: How to use groups effectively. The Journal of Effective Teaching, 11(2): 87-95.

Canagarajah, S. 2011. Translanguaging in the classroom: Emerging issues for research and pedagogy. Applied Linguistics Review, 2:1-27.

Centre for Academic Development. 2013. Improving Learning and Teaching: Group Work and Group Assessment. Wellington: Victoria University of Wellington.

Creese, A. \& Blackledge, A. 2015. Translanguaging and identity in educational settings. Annual Review of Applied Linguistics, 35: 20-35

Csernica, J., Hanyka, M., Hyde, D., Shooter, S., Toole, M. \& Vigeant, M. 2002. Practical guide to teamwork, version 1.1. College of Engineering, Bucknell University.

Cummins, J. 2000. Language, Power and Pedagogy: Bilingual Children in Crossfire. Clevedon, UK: Multilingual Matters.

Department of Higher Education and Training. 2019. Statistics on Post-School Education and Training in South Africa: 2017. Pretoria: Government Printers.

Department of Higher Education and Training. 2015. Report on the Use of African Languages in Higher Education. Pretoria: Government Printers.

Department of Higher Education and Training. 2017. Draft Language Policy for Higher Education. Pretoria: Government Printers.

Dewey, J. 1933. How We Think: A Restatement of the Relation of Reflective Thinking to the Educative Process. Massachusetts: Heath Publishing.

Dlodlo, T.S. 1999. Science nomenclature in Africa: Physics in Nguni. Journal of Research in Science Teaching, 36(3): 322-331.

du Buisson, T. 2017. Facilitating multilingual tutorials at the University of the Free State. Journal of Student Affairs in Africa, 5(2): 151-162.

Eberlein, T., Kampmeier, J., Minderhout, V., Moog, R. S., Platt, T., Varma-Nelson, P. \& White, H. B. 2008. Pedagogies of engagement in science. Biochemistry and Molecular Biology Education, 36(4): 262-273.

Felder, S. \& Brent, R. 2001. Effective strategies for cooperative learning. Journal of Cooperation and Collaboration in College Teaching, 10(2): 69-75.

García, O. \& Sylvan, C. 2011. Pedagogies and practices in multilingual classrooms: Singularities in pluralities. Modern Language Journal, 95(3): 385-400.

Gerring, J. 2008. Case selection for case-study analysis: Qualitative and quantitative techniques. In Box-Steffensmeier,J., Brady, H.E. \& Collier, D. (eds.) The Oxford Handbook of Political Methodology. doi:10.1093/oxfordhb/97801999286546.001.0001 
Hendricks, C. \&Leibowitz, B. 2016. Decolonising universities isn't an easy process-but it has to happen. The Conversation, 23 May. Available at: https://theconversation.com/decolonising-universities-isnt-an-easy-process-but-it-hasto-happen-59604 (Accessed 20 February 2020).

Heugh, K. 2003. Language Policy and Democracy in South Africa: The prospects of equality within rights-based policy and planning. Stockholm: Stockholm University Centre for Bilingual Research on Bilingualism.

Hodges, L.C. 2017. Ten research-based steps for effective group work, IDEA paper \#65, University of Maryland, Baltimore County.

Johnson, D.W., Johnson, R.T. \& Holubec, E.J. 2008. Cooperation in the Classroom. Eighth edition. Edina, MN: Interaction.

Johnson, D.W., Johnson, R.T. \& Smith, K.A. 2014. Cooperative learning: Improving university instruction by basing practice on validated theory. Journal on Excellence in University Teaching, 25(4): 1-26.

Johnson, D.W., Johnson, R.T. \& Smith, K.A. 2006. Active Learning: Cooperation in the University Classroom. Third edition. Edina, MN: Interaction.

Kapp, R. \& Bangeni, B. 2011. A longitudinal study of students' negotiation of language, literacy and identity. South African Linguistics and Applied Linguistics Society, 29(2): 197-208.

Larrivee, B. 2000. Transforming teaching practice: becoming the critically reflective teacher, Reflective Practice, 1(3): 293-307.

Larrivee, B. 2008. Development of a tool to assess teachers' level of reflective practice. Reflective Practice, 9(3): 341-360.

Li Wei. 2014. Who's teaching whom? Co-learning in multilingual classrooms. In May, S. (ed.). The Multilingual Turn: Implications for SLA, TESOL and Bilingual Education. New York: Routledge, 167-190.

Liu, K. 2015. Critical reflection as a framework for transformative learning in teacher education. Educational Review, 67(2): 135-157.

Madiba, M. 2010a. Towards multilingual higher education in South Africa: The University of Cape Town's experience. Language Learning Journal, 38(3): 327-346.

Madiba, M. 2010b. Fast-tracking concept learning to English as additional language (EAL) students through corpus-based multilingual glossaries. Alternation: Interdisciplinary Journal for Study of the Arts and Humanities in Southern Africa, 17(1): 225-248.

Marjorie. L. 1982. Language Policy and Oppression in South Africa. Cultural Survival Quarterly Magazine. Available at: https://www.culturalsurvival.org/publications/cultural-survivalquarterly/language-policy-and-oppression-south-africa. (Accessed 25 April 2019).

Mbembe, A. 2015. Decolonising knowledge and the question of the archive. Lecture delivered at Wits Institute for Social and Economic Research. Available at: http://wiser.wits.ac.za/sites/default/files/private/Achille\%20Mbembe\%20\%Decolonising\% 20Knowledge\%20and\%20Question\%of\%20the\%20Archive.pdf. (Accessed 25 April 2019). 
Mbirimi-Hungwe, V. 2016. Translanguaging as a strategy for group work: Summary writing as a measure for reading comprehension among university students. Southern African Linguistics and Applied Language Studies, 3(3): 241-249.

Middleton, S. 2018. Translanguaging: Facilitating multilingual teaching, University of Cape Town News. Available at: https://www.news.uct.ac.za/republishing-articles/ (Accessed 20 February 2020).

Nudelman, C. 2015. Language in South Africa's higher education transformation: A study of language policies at four universities. Unpublished MPhil Thesis, University of Cape Town, South Africa.

Otheguy, R., Garcia, O. \& Reid, W. 2015. Clarifying translanguaging and deconstructing named languages: A perspective from linguistics. Applied Linguistics Review, 6(3): 281-307.

Paxton, M. 2009. 'It's easy to learn when you using your home language but with English you need to start learning language before you get to the concept': Bilingual concept development in an English medium university in South Africa. Journal of Multilingual and Multicultural Development, 30(4): 345-359.

Race, P. 2007. The Lecturer's Toolkit: A practical guide to Assessment, Learning and Teaching. Third edition. London: Routledge.

Saric, M. \& Steh, B. 2017. Critical reflection in the professional development of teachers: Challenges and Possibilities. Centre for Educational Policy Studies Journal, 7(3): 67-85.

Sekaran, U. \& Bougie, R. 2016. Research Methods for Business: A Skill Building Approach. United Kingdom: John Wiley and Sons.

Smit, R. 2012. Towards a clearer understanding of student disadvantage in higher education: problematising deficit thinking. Higher Education Research \& Development, 31(3): 369380.

Springer, L., Stanne, M.E. \& Donovan, S.S. 1999. Effects of small-group learning on undergraduates in science, mathematics, engineering, and technology: A metaanalysis. Review of Educational Research, 96(1): 21-51.

Tripp, T. \& Rich, P. 2012. Using video to analyze one's own teaching. British Journal of Educational Technology, 43(4): 678-704.

Tyler, R. McKinney, C. \& Guzula, X. 2015. Multilingualism boosts learning and can create new science knowledge too. The Conversation, 1 September Available at: https://theconversation.com/multilingualism-boosts-learning-and-can-create-newscience-knowledge-too-46292. (Accessed 11 November 2019).

Vermunt, J. D. 2014. Teacher Learning and Professional Development. In Krolak-Schwerdt, S., Glock, S. \& Böhmer. M. (eds.). Teachers' Professional Development: Assessment, Training, and Learning. Rotterdam, Boston, Taipei: Sense Publishers, 79-95.

Yin, R.K. 2009. Case Study Research: Design and Methods. 4th edition. Thousand Oaks, CA: Sage. 